\title{
Effect of noninvasive mechanical ventilation in elderly patients with hypercapnic acute-on-chronic respiratory failure and a do-not-intubate order
}

\author{
Paolo Scarpazza' \\ Cristoforo Incorvaia ${ }^{2}$ \\ Giuseppe di Franco' \\ Stefania Raschi' \\ Pierfranco Usai ${ }^{\prime}$ \\ Monica Bernareggi' \\ Cristiano Bonacina' \\ Chiara Melacini' \\ Silvia Vanni' \\ Serena Bencini' \\ Chiara Pravettoni ${ }^{2}$ \\ Giuseppe Di Cara ${ }^{3}$ \\ Mona-Rita Yacoub ${ }^{4}$ \\ Gian Galeazzo \\ Riario-Sforza ${ }^{2}$ \\ Enrico Guffanti ${ }^{5}$ \\ Walter Casali' \\ 'Divisione di Broncopneumotisiologia, \\ Ospedale Civile, Vimercate, Italy; \\ ${ }^{2}$ Pulmonary rehabilitation, Istituti \\ Clinici di Perfezionamento, Milan, Italy; \\ ${ }^{3}$ University Department of Medical \\ and Surgical Specialties and Public \\ Health, Perugia, Italy; ${ }^{4}$ Allergy and \\ Immunology Unit, IRCCS San Raffaele \\ Hospital, Milan, Italy; ${ }^{5}$ Pulmonary \\ rehabilitation, INRCA, \\ Casatenovo, Italy
}

Correspondence: Cristoforo Incorvaia Viale Molise, 69 - 20137 Milano, Italy Tel +39025513852

Fax +3902 57993315

Email cristoforo.incorvaia@gmail.com

\begin{abstract}
Noninvasive mechanical ventilation (NIMV) is effective in the treatment of patients with acute respiratory failure (ARF). It proved to reduce the need of endotracheal intubation (ETI), the incidence of ETI-associated pneumonia, and mortality compared to nonventilated patients. A particular aspect concerns the outcome of NIMV in patients referring to an emergency room (ER) for ARF, and with a do-not-intubate (DNI) status due to advanced age or critical conditions. The aim of our study is to assess the outcome of NIMV in a group of elderly patients with acute hypercapnic ARF who had a DNI status. An overall number of 62 subjects (30 males, 32 females, mean age $81 \pm 4.8$ years, range $79-91$ years) referred to our semi-intensive respiratory department were enrolled in the study. The underlying diseases were severe chronic obstructive pulmonary disease (COPD) in 50/62 subjects, restrictive thoracic disorders in 7/62 subjects, and multiorgan failure in 5/62 subjects. Fifty-four/62 patients were successfully treated with NIMV while 2/62 did not respond to NIMV and were therefore submitted to ETI (one survived). Among NIMV-treated patients, death occurred in 6 patients after a mean of 9.9 days; the overall rate of NIMV failure was $12.9 \%$. Negative prognostic factors for NIMV response proved to be: an older age, a low Glasgow Coma Score, a high APACHE score at admission, a high $\mathrm{PaCO}_{2}$ after 12 hours and a low $\mathrm{pH}$ both after 1 and 12 hours of NIMV. We conclude that elderly patients with acute hypercapnic ARF with a DNI status can be successfully treated by NIMV.

Keywords: acute respiratory failure, noninvasive mechanical ventilation, endotracheal intubation, do-not-intubate, COPD, oxygen therapy
\end{abstract}

\section{Introduction}

Noninvasive mechanical ventilation (NIMV) is effective in the treatment of patients with acute respiratory failure (ARF), as shown by controlled trials and meta-analysis (Bott et al 1993; Kramer et al 1995; Plant et al 2000; Brochard et al 2002; Lightowler et al 2003). In particular, NIMV proved to reduce the need of endotracheal intubation (ETI) (Antonelli et al 1998), to prevent ETI-associated pneumonia (Nourdine et al 1999; Carlucci et al 2001) and to decrease incidence of mortality compared to nonventilated patients (Keenan et al 2004). During last decades NIMV use is continuously increasing (Carlucci et al 2001; Demoule et al 2006), despite consensus documents established the rationale, and therefore also some limitations, to resort to NIMV in severe chronic obstructive lung disease (COPD), restrictive thoracic disorders, and nocturnal hypoventilation (ACCP 1999). Nevertheless, NIMV may have some negative effects, for example the delay in using ETI when the respiratory conditions require such measure, an unsatisfactory outcome in patients with ARF due to severe community acquired pneumonia, and the risk to develop an aspiration pneumonia in patients with altered level of consciousness (Jolliet et al 2001; Metha and Hill 2001; Esteban et al 2004). 
A particular aspect is the outcome of NIMV in patients referring to an emergency department for ARF, who have a do-not-intubate (DNI) status because of elderly age or critical clinical conditions.

The aim of our study was the evaluation of the outcome of NIMV in a group of DNI elderly patients with hypercapnic ARF mainly due to COPD exacerbations.

\section{Materials and methods}

\section{Patients}

Sixty-two patients, 30 males and 32 females, mean age $81 \pm 4.8$ years, range $79-91$ years, with hypercapnic ARF (defined by $\mathrm{PaCO}_{2}>45 \mathrm{~mm} \mathrm{Hg}$ and $\mathrm{pH}<7.35$ ) (Weiss and Hudson 1994), hospitalized in the semi-intensive respiratory medicine unit of Vimercate Hospital, Milan, Italy were enrolled in the study. The inclusion criteria were age $\geq 75$ years and a DNI status, as established by the intensive care physician, on the basis of advanced age and unfavorable clinical status. In Italy, exhaustive laws regulating the matter are currently lacking (Zamparetti et al 2006). In 50 patients the underlying disease was severe COPD (stage 4 GOLD) in 50/62 patients, restrictive thoracic disorders (mainly severe kyphoscoliosis) in $7 / 62$, and multiorgan failure in 5/62. All patients were already treated with long-term oxygen therapy (LTOT).

\section{Methods}

Severity-of-illness classification was assessed by the Acute Physiology and Chronic Health Evaluation (APACHE) II (Knaus et al 1985) and level of consciousness by the Glasgow Coma Score (GCS) (Teasdale and Jennet 1974). Also $\mathrm{PaO}_{2} /$ $\mathrm{FiO}_{2}$ ratio, $\mathrm{PaCO}_{2}, \mathrm{pH}$, respiratory rate, heart rate, and blood pressure were measured. The main characteristics of subjects at baseline are reported in Table 1.

All patients were under treatment with antibiotics, systemic corticosteroids, and bronchodilators. Those with multiorgan failure received the appropriate medical therapy.

NIMV was started in all patients already in the ER by the pneumologist on duty, and was continued in the semi-intensive respiratory medicine unit. NIMV was performed in 59 patients by pressure support, bilevel mode, and in 3 patients by volume support mode. Assisted controlled ventilation, setting a lower than spontaneous respiratory rate was used in conscious patients, while in the others, a controlled ventilation was used. Ventilators models Helia and Elisee 150 from Vivisol (Savigny Le Temple, France), with oronasal masks as interface, were used. Inspiratory (IPAP) and expiratory positive airway pressure (EPAP) were set according to
Table I Characteristics of patients at admittance

\begin{tabular}{ll}
\hline Parameter & Mean value (SD) \\
\hline GCS & $11.1 \pm 3.5$ \\
APACHE 2 score & $27.2 \pm 5.8$ \\
$\mathrm{PaO}_{2}$ & $49.0 \pm 16.5$ \\
$\mathrm{PaCO}_{2}$ & $85.6 \pm 18.0$ \\
$\mathrm{pH}$ & $7.23 \pm 0.09$ \\
$\mathrm{HCO}_{3}$ & $35.6 \pm 6.5$ \\
$\mathrm{FiO}_{2}$ & $0.28 \pm 0.1$ \\
$\mathrm{Respiratory}$ rate & $31.9 \pm 8.6$ \\
Heart rate & $99.3 \pm 22.2$ \\
Systolic blood pressure & $98.8 \pm 21.5$ \\
\hline
\end{tabular}

Abbreviations: GCS, glasgow coma score; SD, standard deviation.

patient's tolerance and blood gas parameters. All blood gas parameters were measured after one and 12 hours of continuous ventilation and at discharge.

The local Ethical Committee approved the procedures of the study, and patients or their relatives (depending on patient's clinical conditions) gave their verbal informed consent to NIMV.

\section{Statistical analysis}

The results were expressed as mean \pm SD. Mean values of considered parameters in patients successfully or unsuccessfully treated by NIMV were compared, for both intergroup and intragroup analysis, using ANOVA test. The one-way ANOVA was used to examine difference between groups at the enrolment and ANOVA with post-hoc analysis was used for repeated measures to test the trend of parameters for each group of patients, considering significant a p value $<0.05$. The small number of patients unsuccessfully treated prevented the comparison of categorical variables or the analysis of odds ratio by multivariate logistic regression.

\section{Results}

Fifty-four/62 patients were successfully treated with NIMV, and discharged after a mean duration of hospitalization of $13.7 \pm 5.1$ days. In two patients significant changes in $\mathrm{PaCO}_{2}$ and $\mathrm{pH}$ values did not occur and, following the consent by their relatives, they were submitted to ETI, and one survived. In other six patients the treatment was unable to prevent death, which occurred after a mean of $9.9 \pm 8.3$ days of hospitalization. One subject, a 88-year-old male, died before the 12 hours assessment: he had an exacerbation in severe COPD, with a GCS score of 6, an APACHE score of 37, a $\mathrm{PaO}_{2} / \mathrm{FiO}_{2}$ ratio of 145, a $\mathrm{PaCO}_{2}$ of $96 \mathrm{~mm} \mathrm{Hg}$, and 
a pH of 6.9; after one hour of NIMV in bilevel mode, with IPAP $25 \mathrm{~cm} \mathrm{H}_{2} \mathrm{O}$ and EPAP $7 \mathrm{~cm} \mathrm{H}_{2} \mathrm{O}$, the ratio $\mathrm{PaO}_{2} / \mathrm{FiO}_{2}$ moved to 103 , the $\mathrm{PaCO}_{2}$ to $88 \mathrm{~mm} \mathrm{Hg}$, and the $\mathrm{pH}$ to 7.01 . In the other six cases, death occurred for pneumonia (2/6), multiorgan failure (2/6), or ARF (2/6). The NIMV failure in the studied patients was $12.9 \%$.

Table 2 reports the mean age, GCS and APACHE scores, and blood gas parameters at admission, and after both 1 and 12 hours in patients successfully or unsuccessfully treated. NIMV-nonresponders had a lower GCS and an higher APACHE score at baseline compared to NIMV-responders, while no differences in $\mathrm{PaO}_{2} / \mathrm{FiO}_{2}, \mathrm{PaCO}_{2}$ or $\mathrm{pH}$ were observed. NIMV-nonresponders had a significantly higher mean value of $\mathrm{PaCO}_{2}$ after 12 hours and a significantly lower $\mathrm{pH}$ value both after 1 and 12 hours. Intra-group comparison by ANOVA test with post-hoc analysis showed no significant change in $\mathrm{PaO}_{2} /$ $\mathrm{FiO}_{2}$ and significant improvement in $\mathrm{PaCO}_{2}$ and $\mathrm{pH}(\mathrm{p}<0.0001)$ in successfully treated, while no significant change for any parameter was found in unsuccessfully treated patients.

Thirty-five/54 patients who recovered after NIMV continued ventilation at home to control hypercapnia $\left(\mathrm{PaCO}_{2}=52.5 \mathrm{~mm} \mathrm{Hg}\right)$, while $19 / 54$ needed only oxygen therapy $\left(\mathrm{PaCO}_{2}=45.4 \mathrm{~mm} \mathrm{Hg}\right)(\mathrm{p}=0.001)$.

\section{Discussion}

The effectiveness of NIMV in ARF patients was clearly demonstrated by numerous randomized trials (Bott et al 1993;
Kramer et al 1995; Wisocki et al 1995; Antonelli et al 2000; Plant et al 2000; Brochard et al 2002; Ferrer et al 2003). Studies regarding respiratory failure resulting from COPD exacerbations were included in a meta-analysis, that confirmed the favorable outcome of NIMV in such population (Lightowler et al 2003). However, the optimal settings and performances deriving from randomized trials could not be applicable in routine practice of NIMV, and therefore data deriving from observational studies are also important. A recent prospective observational study conducted in France on 524 patients reported a significantly better outcome in subjects with acute-on-chronic respiratory failure compared to those with acute de novo respiratory failure, showing a mortality rate of $20 \%$ and $41 \%$, respectively (Demoule et al 2006).

Age is an important issue to be considered; the increasing duration of life in the general population and the increasing life expectancy in COPD patients due to LTOT make common to find elder patients with severe ARF in ER. In these patients, the balance for ETI - as assessed by the ER physician - is often critical, leaving NIMV as the only treatment option.

The present study, that included elderly patients (mean age of 81 years) with acute-on-chronic respiratory failure (all patients were on LTOT), shows a low mortality rate (about 13\%), that is particularly favourable in this setting. In fact previous studies reported the older age as a predictor of NIMV failure in patients with ARF (Antonelli et al 2001).

Table 2 Difference in considered parameters in successful and unsuccessful NIMV

\begin{tabular}{|c|c|c|c|}
\hline & Successful NIMV & Unsuccessful NIMV & Significance $(p)$ \\
\hline Mean age (years) & $80.46 \pm 4.61$ & $84.75 \pm 4.30$ & 0.016 \\
\hline GCS & $11.46 \pm 3.23$ & $8.12 \pm 3.87$ & 0.01 \\
\hline APACHE 2 score & $26.62 \pm 5.48$ & $31.75 \pm 6.14$ & 0.018 \\
\hline $\mathrm{PaO}_{2} / \mathrm{FiO}_{2}$ & $178.96 \pm 42.82$ & $164.13 \pm 54.47$ & n.s. \\
\hline $\mathrm{PaO}_{2} / \mathrm{FiO}_{2}$ after I hour & $155.68 \pm 52.29$ & $166.88 \pm 49.32$ & n.s. \\
\hline $\mathrm{PaO}_{2} / \mathrm{FiO}_{2}$ after 12 hours & $174.33 \pm 64.79$ & $161.14 \pm 64.54$ & n.s. \\
\hline $\mathrm{PaCO}_{2}$ & $84.77 \pm 14.45$ & $92.75 \pm 35.48$ & n.s. \\
\hline $\mathrm{PaCO}_{2}$ after I hour & $70.19 \pm 12.19$ & $81.50 \pm 28.03$ & n.s. $(0.052)$ \\
\hline $\mathrm{PaCO}_{2}$ after 12 hours & $58.10 \pm 9.02$ & $73.28 \pm 26.77^{*}$ & 0.003 \\
\hline $\mathrm{pH}$ & $7.24 \pm 0.08$ & $7.18 \pm 0.16$ & n.s. \\
\hline $\mathrm{pH}$ after I hour & $7.32 \pm 0.05$ & $7.21 \pm 0.15$ & $<0.001$ \\
\hline $\mathrm{pH}$ after 12 hours & $7.40 \pm 0.06$ & $7.33 \pm 0.09 *$ & 0.01 \\
\hline $\mathrm{HCO}_{3}$ & $35.96 \pm 6.31$ & $33.64 \pm 7.74$ & n.s. \\
\hline $\mathrm{HCO}_{3}$ after I hour & $35.37 \pm 5.97$ & $33.04 \pm 8.43$ & n.s. \\
\hline $\mathrm{HCO}_{3}$ after 12 hours & $34.95 \pm 4.41$ & $34.86 \pm 9.12$ & n.s. \\
\hline
\end{tabular}

Abbreviations: GCS, glasgow coma score; NIMV, noninvasive mechanical ventilation. Note: *One patient died before 12 hours and is not considered here. 
Also in our study age was a critical factor, since the mean age of the NIMV-nonresponders was significantly higher compared to that of the responders (87.4 years versus 80.5 years). Regardless the age, other studies on COPD patients with DNI status reported a mortality rate of $34 \%-43 \%$ (Levy et al 2004; Schettino et al 2005; Fernandez et al 2007).

In our study, the small number of subjects who failed to respond to NIMV — eight, with seven deaths and one patient undergoing ETI successfully-did not allow us to use the best analysis in evaluating risk factors, ie, odds ratio and $95 \%$ confidence interval. Some findings although emerge with the simpler analysis used.

Firstly, the severe clinical conditions of patients, defined by a significantly worse score both to GCS and APACHE 2 , in patients who failed to respond to NIMV, confirms previous observations obtained with the same parameters (Confalonieri et al 2005; Phua et al 2006) or using other severity-of-illness classification, as the Simplified Acute Physiology Score or the Logistic Organ Dysfunction (Antonelli et al 2001; Demoule et al 2006). In particular, a GCS lower than 11 and an APACHE II score higher than 29 were found to predict a failure risk of NIMV in patients with COPD exacerbation (Phua et al 2005). Moreover, a high APACHE II score proved to predict NIMV failure in hypercapnic ARF due both to COPD and non-COPD conditions (Celli and MacNee 2004). Such data agree with our findings, obtained in COPD patients but also with other conditions underlying ARF.

Concerning functional parameters, baseline ratio of $\mathrm{PaO}_{2} / \mathrm{FiO}_{2}$ was not significantly different in successful NIMV compared with unsuccessful NIMV. Also baseline $\mathrm{PaCO}_{2}$ was not significantly higher in unsuccessful than in successful NIMV, while the difference in mean value was close to significance after 1 hour $(\mathrm{p}=0.052)$ and significant after 12 hours of NIMV $(p=0.003)$. Indeed, the $\mathrm{pH}$ value is the major parameter that indicates the need of ventilation in ARF patients (Celli and MacNee 2004) and in our population $\mathrm{pH}$ mean value was significantly lower in the failure group than in successful one, both after 1 hour $(\mathrm{p}<0.001)$ and after 12 hours of NIMV $(p=0.01)$. In the study by Confalonieri and colleagues (2005) a pH value $<7.25$ increased by more than $90 \%$ the risk of failure of NIMV. This disagrees with our data, since most of our successfully treated patients had a $\mathrm{pH}$ lower than 7.25. However, that study included only COPD exacerbations, while our patients had also different underlying diseases, that make the comparison not completely appropriate. The intra-group analysis of our patients showed a significant improvement of $\mathrm{pH}$ and $\mathrm{PaCO}_{2}$ only in successfully treated subjects, but the overlapping between the two groups in physiological parameters makes difficult to predict the response to NIMV in this kind of patients. Thus, the baseline severity of the clinical status appears to be the most important factor in influencing the outcome.

In the 54 NIMV-responders a rapid clinical improvement was achieved, allowing their discharge after about two weeks of hospitalization. Such findings offer some outlook about the need "to evaluate the clinical outcomes of using noninvasive positive pressure ventilation for patients who choose to forego endotracheal intubation and to examine the perspectives of patients, families, and clinicians on use of NPPV in these contexts" (Curtis et al 2007). Moreover, NIMV may improve the end of life care in advanced COPD, where there is evidence of unmet needs (Spathis and Booth 2008).

In conclusion, this study shows that elderly patients with ARF from COPD exacerbations (but also from other respiratory disorders) and with a DNI status can be successfully treated by NIMV.

\section{Disclosure}

The authors report no conflicts of interest in this work.

\section{References}

[ACCP] American College of Chest Physicians 1999. A consensus conference report. Clinical indications for non-invasive positive pressure ventilation in chronic respiratory failure due to restrictive lung disease, COPD, and nocturnal hypoventilation. Chest, 116:521-34.

Antonelli M, Conti G, Rocco M, et al. 1998. A comparison of noninvasive positive-pressure ventilation and conventional mechanical ventilation in patients with acute respiratory failure. $N$ Engl J Med, 339:429-35.

Antonelli M, Conti G, Bufi M, et al. 2000. Noninvasive ventilation for treatment of acute respiratory failure in patients undergoing solid organ transplantation: a randomized trial. JAMA, 283:235-41.

Antonelli M, Conti G, Moro ML, et al. 2001. Predictors of failure of noninvasive positive pressure ventilation in patients with acute hypoxemic respiratory failure: a multicenter study. Intensive Care Med, 27:1718-28.

Bott J, Carroll MP, Conway JH, et al. 1993. Randomised controlled trial of nasal ventilation in acute ventilatory failure due to chronic obstructive airways disease. Lancet, 341:1555-7.

Brochard L, Mancebo J, Elliott MW. 2002. Noninvasive ventilation for acute respiratory failure. Eur Respir J, 19:712-21.

Carlucci A, Richard JC, Wysocki M, et al. 2001. Noninvasive versus conventional mechanical ventilation. An epidemiologic survey. Am J Respir Crit Care Med, 163:874-80.

Celli BR, MacNee W, ATS/ERS Task Force. 2004. Standards for the diagnosis and treatment of patients with COPD: a summary of the ATS/ERS position paper. Eur Respir J, 23:932-46.

Confalonieri M, Garuti G, Cattaruzza MS, et al. 2005. A chart of failure risk for noninvasive ventilation in patients with COPD exacerbation. Eur Respir J, 25:1130-1.

Curtis JR, Cook DJ, Sinuff T, et al. 2007. Noninvasive positive pressure ventilation in critical and palliative care setting: understanding the goals of therapy. Crit Care Med, 35:932-9.

Demoule A, Girou E, Richard JC, et al. 2006. Increased use of noninvasive ventilation in French intensive care units. Intensive Care Med, $32: 1747-55$. 
Demoule A, Girou E, Richard JC, et al. 2006. Benefits and risks of success or failure of nonvasive ventilation. Intensive Care Med, 32:1756-65.

Esteban A, Frutos-Vivar F, Ferguson ND, et al. 2004. Noninvasive positive pressure ventilation for respiratory failure after extubation. $N$ Engl $J$ Med, 350:2452-60.

Fernandez R, Baigorri F, Artigas A. 2007. Noninvasive ventilation in patients with "do-not intubate" orders: medium-term efficacy depends critically on patient selection. Intensive Care Med, 33:350-4.

Ferrer M, Esquinas A, Leon M, et al. 2003. Noninvasive ventilation in severe hypoxemic respiratory failure: a randomized clinical trial. Am J Respir Crit Care Med, 168:1438-44.

Jolliet P, Abajo B, Pasquina B, et al. 2001. Noninvasive pressure support ventilation in severe community acquired pneumonia. Intensive Care Med, 27:812-21.

Keenan SP, Sinuff T, Cook DJ, et al. 2004. Does noninvasive positive pressure ventilation improve outcome in acute hypoxemic respiratory failure? A systematic review. Crit Care Med, 32:2516-23.

Knaus WA, Draper EA, Wagner DP, et al. 1985. APACHE II: a severity of disease classification system. Crit Care Med, 13:818-29.

Kramer N, Meyer TJ, Meharg J, et al. 1995. Randomized, prospective trial of noninvasive positive pressure ventilation in acute respiratory failure. Am J Respir Crit Care Med, 151:1799-806.

Levy M, Tanios MA, Nelson D, et al. 2004. Outcomes of patients with the do-not-intubate orders treated with non-invasive ventilation. Crit Care Med, 32:2002-7.

Lightowler JV, Wedzicka JA, Elliot MW, et al. 2003. Non-invasive positive pressure ventilation to treat respiratory failure resulting from exacerbations of chronic obstructive pulmonary disease: Cochrane systematic review and meta-analysis. $B M J, 326: 185$.
Nourdine K, Combes P, Carton MJ, et al. 1999. Does noninvasive ventilation reduce the ICU nosocomial infection risk? A prospective clinical survey. Intensive Care Med, 25:567-73.

Metha S, Hill NS. 2001. Non-invasive ventilation. Am J Respir Crit. Care Med, 163:540-77.

Phua J, Kong K, Lee KH, et al. 2005. Noninvasive ventilation in hypercapnic acute respiratory failure due to chronic obstructive pulmonary disease vs. other condition: effectiveness and predictors of failure. Intensive Care Med, 31:533-9.

Plant PK, Owen JL, Elliot MW. 2000. Early use of noninvasive ventilation for acute exacerbations of chronic obstructive pulmonary disease on general respiratory wards: a multicentre randomised controlled trial. Lancet, 355:1931-5.

Schettino G, Altobelli N, Kacmarek RM. 2005. Noninvasive positive pressure ventilation reverses acute respiratory failure in select "do-not-intubate" patients. Crit Care Med, 33:1976-82.

Spathis A, Booth S. 2008. End of life care in chronic obstructive pulmonary disease: in search of a good death. Int J Chron Obstruct Pulmon Dis, 3:11-29.

Teasdale G, Jennett B. 1974. Assessment of coma and impaired consciousness: a practical scale. Lancet, 2:81-4.

Weiss SM, Hudson LD. 1994. Outcome from respiratory failure. Crit Care Clin, 10:197-215.

Wysocki M, Tric L, Wolff MA, et al. 1995. Noninvasive pressure support ventilation in patients with acute respiratory failure. A randomized comparison with conventional therapy. Chest, 107:761-8.

Zamparetti N, Proietti R. 2006. End of life in the ICU: laws, rules and practices: the situation in Italy. Intensive Care Med, 32:2067-9. 
